\title{
Carbohydrate Metabolism in Phenylketonuria
}

\author{
R. MALCOLM STEWART, M.D., ${ }^{(42)}$ SHAI HEMLI, M.D., EDWIN H. KOLODNY, M.D., \\ ALEXANDER L. MILLER, M.D., and JOHANNA A. PALLOTTA, M.D. \\ The Eunice Kennedy Shriver Center for Mental Retardation at the Walter E. Fernald State School, The \\ Massachusetts General Hospital, The Beth Israel Hospital, The Mailman Research Center at McLean Hospital, and \\ the Departments of Neurology, Psychiatry and Medicine, Harvard Medical School, Boston, Massachusetts, USA
}

\section{Summary}

Carbohydrate metabolism was studied in 6 adult patients with phenylketonuria both on a low phenylalanine and an unrestricted institutional diet. Tolerance tests included PO glucose, PO phenylalanine, and combined glucose and phenylalanine loading. Glucose, insulin, pyruvate, lactate, and phenylalanine were sampled at $0,1 / 2,1,2,3$, and $4 \mathrm{hr}$. Fasting glucose levels were normal as were mean glucose values after challenge. Basal insulin secretion, as well as insulin response, to glucose challenge and to combined phenylalanine and glucose loading appeared normal. Insulin response to phenylalanine alone, however, was lower than expected in the phenylketonuria patients. Both off and on low phenylalanine diet, blood pyruvate and lactate values were also normal. Thus, our data from blood did not show evidence of the abnormalities in glucose and pyruvate metabolism which have been proposed to occur in phenylketonuric patients but did suggest that the potency of phenylalanine as an insulin secretagogue is diminished by chronic hyperphenylalaninemia.

\section{Speculation}

Carbohydrate metabolism following a glucose load and measured in whole blood appears normal in phenylketonuria. In contrast, the insulin response to a phenylalanine load appears decreased. Chronic hyperphenylalaninemia may produce a state of subsensitivity of the pancreas for the insulin response to an acute phenylalanine load.

Phenylketonuria (PKU) due to phenylalanine hydroxylase deficiency is an inherited metabolic disorder characterized by a defective conversion of phenylalanine to tyrosine. This enzyme is primarily found in the liver. In the untreated state, abnormally large concentrations of phenylalanine, phenylpyruvate, and other metabolites are present in blood and urine, whereas tyrosine levels are decreased. Although restriction in dietary phenylalanine can prevent the severe mental retardation which otherwise occurs, the mechanisms responsible for brain damage in this disease are not well understood. Phenylalanine is known to interfere with amino acid transport $(29,37)$ and to inhibit enzymes of the glycolytic pathway in brain $(5,14,28,39)$. Phenylpyruvate, a phenylalanine metabolite, has been reported to inhibit pyruvate dehydrogenase $(21,24)$, hepatic pyruvate carboxylase (36), and brain fatty acid synthesis $(22,34)$. Inhibition of pyruvate utilization could result in accumulation of pyruvate and lactate in the blood of phenylketonuric patients. In fact, greatly increased lactate and pyruvate levels have been reported in the blood and urine of individuals with PKU $(24,36)$. Interest in carbohydrate metabolism in PKU has also been stimulated by reports of phenylalanine effects on insulin secretion $(11,12,17,30)$ on glucose transport $(38)$, on glucose metabolism $(15,16,20)$, and on pyruvate metabolism $(28$, 39). In this study, we evaluated six retarded individuals with PKU on and off a low phenylalanine diet to further define the status of carbohydrate metabolism in PKU.

\section{MATERIALS AND METHODS}

\section{SUBJECTS}

Six residents, 4 males and 2 females, of the Walter E. Fernald State School were selected from a group of 15 patients with PKU previously studied (35). The diagnosis of PKU was based on the clinical features of mental retardation, hypopigmentation, and hyperactivity combined with an elevated serum phenylalanine level greater than $20 \mathrm{mg} / \mathrm{dl}$. One subject received phenytoin to control seizures and continued on this medication throughout all phases of the study. Each participated in regular daily programs of moderate physical activity geared to their abilities. There was no family history of diabetes mellitus or other endocrinopathy. Their ages ranged from 19 to 53 (see Table 1). Informed consent was obtained from the guardians and families of each of the subjects participating in the study in accordance with United States Department of Health, Education, and Welfare and Commonwealth of Massachusetts Department of Mental Health regulations concerning human studies. These subjects served as their own controls off and on diet. In addition, three of the investigators served as normal controls.

\section{METABOLIC DIETS}

The subjects were fed the regular unrestricted high carbohydrate institutional diet or a low phenylalanine diet. None was on any other dietary restrictions at the beginning of the study. The low phenylalanine diet used during the second phase of the study was modeled after that used by the Boston Children's Hospital Medical Center Phenylketonuria Clinic. In this diet, allowable dietary protein and phenylalanine are calculated as follows: body weight $(\mathrm{kg}) \times 15 \mathrm{mg}$ phenylalanine per $\mathrm{kg}$ yields the maximum daily phenylalanine; body weight $(\mathrm{kg}) \times 0.8 \mathrm{~g}$ protein $/ \mathrm{kg}$ yields daily protein allowance. Daily protein allowance $\times 80 \%$ yields daily protein from Lofenalac (Mead, Johnson and Co.). This diet was supplemented with appropriate fruits, vegetables, and low phenylalanine bread and milk. Caloric intake was adjusted to maintain a stable weight. One patient received $375 \mathrm{mg}$ and four received $500 \mathrm{mg}$ total $(7.8$ to $11.4 \mathrm{mg} / \mathrm{kg}$ ) of phenylalanine daily (50 to $75 \%$ of maximum allowable), an amount which maintained the serum phenylalanine value between 5 and $10 \mathrm{mg} / \mathrm{dl}$. Specific flavorings were added to suit the taste of each individual subject. Their actual intake at each meal was monitored so that adjustments could be made that would ensure an adequate caloric intake. However, in spite of numerous modifications to the diet, subject 6 could not adjust to it and began losing weight. His phenylalanine level paradoxically increased from 20 to $40 \mathrm{mg} / \mathrm{dl}$, presumably from skeletal muscle catabolism (see Table 1).

\section{TOLERANCE TESTS}

The subjects were evaluated with a series of tolerance tests during both the unrestricted and low phenylalanine dietary phases, so that the patients served as their own controls. Each dietary 
Table 1. Phenylalanine response after 60 days on diet in subjects with PKU

\begin{tabular}{|c|c|c|c|c|c|c|c|}
\hline \multirow[b]{2}{*}{ Subject } & \multirow[b]{2}{*}{ Age } & \multirow[b]{2}{*}{ Sex } & \multirow{2}{*}{$\frac{\text { Wt }(\mathrm{kg})}{\text { Initial Final }}$} & \multirow{2}{*}{$\begin{array}{c}\text { Caloric } \\
\text { intake } \\
\text { (daily average) }\end{array}$} & \multirow{2}{*}{$\begin{array}{c}\text { Dietary } \\
\text { phenylalanine }(\mathrm{mg} / \mathrm{kg}) \\
\text { (daily average) }\end{array}$} & \multicolumn{2}{|c|}{ Serum phenylalanine $(\mathrm{mg} / \mathrm{dl})$} \\
\hline & & & & & & Off diet & On diet \\
\hline 1 & 25 & $\mathrm{~F}$ & $45.0 \quad 47.0$ & 3650 & 11.1 & 38.0 & 4.5 \\
\hline 2 & 53 & M & $63.0 \quad 65.5$ & 2850 & 7.9 & 29.0 & 10.0 \\
\hline 3 & 42 & M & $48.0 \quad 45.0$ & 3000 & 11.4 & 36.0 & 5.5 \\
\hline 4 & 27 & $\mathrm{~F}$ & $42.5 \quad 43.0$ & 2650 & 8.8 & 34.5 & 7.5 \\
\hline 5 & 19 & M & $64.0 \quad 63.0$ & 3825 & 7.8 & 47.5 & 10.5 \\
\hline 6 & 50 & M & $65.5 \quad 63.0$ & 1 & 1 & 20.0 & 40.5 \\
\hline
\end{tabular}

${ }^{1}$ Subject 6 did not tolerate the low phenylalanine diet so that stable caloric and dietary phenylalanine intake values on this individual could not be adequately determined for the second part of the study. Final weight and serum phenylalanine value shown for this subject were obtained (26) after 30 days of diet.

phase was maintained for at least 2 months before the start of these tests (26). The challenges included a PO glucose tolerance test $(1.75 \mathrm{~g} / \mathrm{kg})$ alone, PO phenylalanine alone $(100 \mathrm{mg} / \mathrm{kg})$, and both simultaneously in combination $(6,7,9)$. All of these treatments followed an overnight fast and were ingested over a period of $5 \mathrm{~min}$ or less.

Samples were obtained for glucose, insulin, pyruvate, lactate, and phenylalanine at $0,1 / 2,1,2,3$, and $4 \mathrm{hr}$. For the IV glucose challenge, $50 \%$ dextrose in water solution $(0.5 \mathrm{gm} / \mathrm{kg})$ was given as a bolus over a 5 -min period. Samples were collected at $0,5,10$, $20,30,40,50,60,120,180$, and $240 \mathrm{~min}$. To minimize stress to the subject, an indwelling venous catheter was used at most times for blood sampling. Glucose was measured by a glucose oxidase technique (27). In studies where glucose, pyruvate, and lactate were each assayed in the same specimens, their determinations were obtained by enzymatic methods adapted to the spectrophotometer (25). Phenylalanine and tyrosine were measured by a manual fluorometric assay $(3,4)$. A double-antibody radioimmunoassay was used for quantitation of plasma insulin $(19,31,40)$ and glucagon (2).

\section{RESULTS}

\section{SERUM PHENYLALANINE}

Long-term monitoring of serum phenylalanine (Table 1) demonstrated that the low phenylalanine diet was effective in lowering the serum phenylalanine levels in subjects one to five from a range of 29 to $48 \mathrm{mg} / \mathrm{dl}$ before diet to values of 4.5 to $10.5 \mathrm{mg} / \mathrm{dl}$ while on the diet (26). Lower levels were not attempted because hypoglycemia has been reported in phenylalanine-deficient diets (10). Paradoxically, subject 6 demonstrated an increase from 20 to 40.5 $\mathrm{mg} / \mathrm{dl}$ when the low phenylalanine diet was instituted.

\section{SERUM GLUCOSE}

Mean serum glucose levels are given in Table 2. Fasting glucose levels for PKU subjects were approximately 90 to $100 \mathrm{mg} / \mathrm{dl}$ (normal). There were no significant differences in serum glucose between subjects on and off the low phenylalanine diet when challenged with glucose alone, phenylalanine alone, or glucose plus phenylalanine. No consistent difference was noted for total glucose area (1) off or on a low phenylalanine diet in response to glucose challenge (Fig. 1A).

\section{PLASMA INSULIN}

Plasma insulin values are shown in Table 2. Fasting plasma insulin values for PKU subjects were approximately $10 \mu \mathrm{U} / \mathrm{ml}$ (normal). The mean peak plasma insulin level was observed one hr after a PO glucose load either given alone or in combination with phenylalanine. This peak response of insulin to glucose challenge alone reached a concentration of $73.5 \pm 30.7 \mu \mathrm{U} / \mathrm{ml}$ when off diet and $88.3 \pm 30.5 \mu \mathrm{U} / \mathrm{ml}$ when on diet (no significant difference). No consistent difference was noted for total insulin areas (1) after glucose challenge off or on the diet (Fig. 1B). The peak responses for a combined glucose and phenylalanine challenge were $92.7 \pm 38.4$ and $91.0 \pm 30.2 \mu \mathrm{U} / \mathrm{ml}$, off and on the low phenylalanine diet, respectively. Insulin response to PO glucose loading was generally higher than by intravenous infusion (Fig. 2).

The subjects off diet showed little insulin response to PO phenylalanine (Table 2). The same was true on diet except for one subject (subject 4) who had no response while off the diet, but did respond with an increase in plasma insulin when on diet. The plasma insulin values of this subject, along with those of three control subjects are shown in Figure 3.

Glucagon assays were not routinely performed. Plasma glucagon in subject 4 rose as expected in response to phenylalanine loading while on the diet. Comparable values off the diet were not obtained.

\section{BLOOD PYRUVATE AND LACTATE}

The fasting levels of blood pyruvate (Table 3) were similar off $(0.06$ to $0.07 \mu \mathrm{mole} / \mathrm{ml})$ and on $(0.05$ to $0.07 \mu \mathrm{mole} / \mathrm{ml})$ the low phenylalanine diet. Pyruvate levels rose to a similar degree in response to $\mathrm{PO}$ glucose loading with a peak at one hr on the diet and at $2 \mathrm{hr}$ when off the diet. Lactate levels rose in response to the PO glucose load both on and off the diet. The lactate response to the administration of PO phenylalanine in combination with glucose was similar to that of PO glucose alone.

\section{DISCUSSION}

Wapnir and Lifshitz (38), in one well-studied case of a woman with PKU reported a slight impairment $(-10.3 \%)$ in the small intestinal absorption of glucose which was not changed after treatment with a low phenylalanine diet. The mean values for the glucose tolerance tests of this group of PKU patients were normal. These data suggest that neither the blood level of phenylalanine nor the presence simultaneously of a phenylalanine load significantly affected the small intestinal absorption of glucose.

The relationship of phenylalanine to insulin and glucagon secretion and blood glucose levels is complex. Several amino acids including phenylalanine are known to stimulate insulin secretion in man $(11,12)$; and increased insulin sensitivity and intolerance to starvation have been reported in subjects with PKU (30). However, chronically increased phenylalanine levels do not raise basal levels of insulin or cause B-islet cell fatigue in the pancreas (18) and phenylalanine does not promote increased insulin secretion in the experimentally perfused rat pancreas (23). Our studies confirm that baseline insulin levels are not significantly altered in PKU, but do indicate a lack of responsiveness to phenylalanine as an insulin secretagogue. The data from one subject suggest that this hyposensitivity to phenylalanine stimulation of insulin release may sometimes be reversible with diet.

Phenylalanine is also considered to be a gluconeogenic amino acid. An initial increase in the serum glucose level may be seen in normal subjects after phenylalanine loading (13) and a slight increase occurred in our patients both on a regular and low phenylalanine diet. This initial rise may be explained in part by 
Table 2. Serum glucose and plasma insulin response in PKU patients after oral glucose and phenylalanine challenge ${ }^{1}$

\begin{tabular}{|c|c|c|c|c|c|c|}
\hline \multirow{2}{*}{$\begin{array}{l}\text { Treatment } \\
\text { (diet) }\end{array}$} & \multicolumn{2}{|c|}{ Glucose } & \multicolumn{2}{|c|}{ Phenylalanine } & \multicolumn{2}{|c|}{ Glucose + phenylalanine } \\
\hline & Regular & Low phenylalanine & Regular & Low phenylalanine & Regular & Low phenylalanine \\
\hline
\end{tabular}

Serum glucose $(\mathrm{mg} / \mathrm{dl})$

$\begin{array}{rrcll}\mathrm{F} & 90.3 \pm 3.1^{2} & 89.2 \pm 2.6 & 81.3 \pm 7.7 & 85.1 \pm 5.9 \\ 30 & 133.2 \pm 8.5 & 126.2 \pm 12.9 & 87.0 \pm 3.9 & 86.4 \pm 6.7 \\ 1 & 120.4 \pm 8.5 & 114.6 \pm 17.5 & 88.2 \pm 4.6 & 88.5 \pm 1.3 \\ 2 & 98.1 \pm 7.1 & 104.0 \pm 18.0 & 96.5 \pm 2.4 & 93.2 \pm 3.4 \\ 3 & 85.8 \pm 7.0 & 75.6 \pm 20.6 & 97.2 \pm 10.0 & 94.0 \pm 4.3 \\ 4 & 79.5 \pm 7.5 & 71.2 \pm 6.8 & 95.4 \pm 6.4 & 88.0 \pm 5.4\end{array}$

$$
\begin{aligned}
91.8 & \pm 3.9 \\
143.0 & \pm 6.0 \\
139.8 & \pm 6.5 \\
99.0 & \pm 11.7 \\
89.4 & \pm 11.3 \\
87.6 & \pm 3.7
\end{aligned}
$$

$$
\begin{aligned}
89.3 & \pm 6.8 \\
137.3 & \pm 23.5 \\
109.3 & \pm 23.7 \\
95.6 & \pm 20.7 \\
61.3 & \pm 11.3 \\
74.3 & \pm 16.8
\end{aligned}
$$

Plasma insulin $(\mathrm{uU} / \mathrm{ml})$

$\begin{array}{rl}\text { F } & 10.4 \pm 1.8 \\ 30 & 68.6 \pm 21.6 \\ 1 & 73.5 \pm 30.7 \\ 2 & 57.0 \pm 19.4 \\ 3 & 29.1 \pm 9.1 \\ 4 & 12.7 \pm 1.5\end{array}$

$$
\begin{aligned}
& 10.3 \pm 2.7 \\
& 76.4 \pm 12.7 \\
& 88.3 \pm 30.5 \\
& 57.7 \pm 9.7 \\
& 30.4 \pm 8.6 \\
& 11.6 \pm 2.6
\end{aligned}
$$$$
9.9 \pm 0.8
$$$$
8.9 \pm 1.8
$$$$
9.1 \pm 1.7
$$$$
10.3 \pm 1.2
$$

$\begin{aligned} 9.1 & \pm 1.5 \\ 14.2 & \pm 7.3 \\ 11.4 & \pm 3.8 \\ 9.7 & \pm 2.1 \\ 9.8 & \pm 2.5 \\ 10.1 & \pm 2.7\end{aligned}$

$10.2 \pm 1.4$
$82.3 \pm 21.9$
$92.7 \pm 38.4$
$69.9 \pm 21.1$
$38.5 \pm 8.8$
$22.0 \pm 11.2$

$10.4 \pm 2.6$

$77.6 \pm 27.1$

$91.0 \pm 30.2$

$62.6 \pm 12.4$

$10.0 \pm 1.5$

$8.2 \pm 1.1$

$15.8 \pm 6.5$

$10.8 \pm 5.1$

${ }^{1}$ Subjects off diet had the regular institutional diet. Subjects on diet were given Lofenalac to lower the serum phenylalanine to a level of 5 to $10 \mathrm{mg} /$ dl. Patients were fasting overnight before the acute challenge with glucose $(75 \mathrm{mg} / \mathrm{kg})$, phenylalanine $(100 \mathrm{mg} / \mathrm{kg})$, or combination of both $(N=6 \mathrm{off}$ diet and 5 on diet).

${ }^{2}$ Mean \pm S.E.

GLUCOSE RESPONSE TO ORAL LOADING

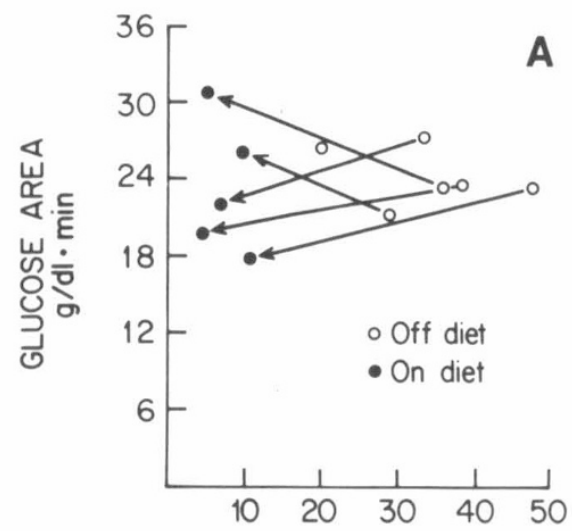

INSULIN RESPONSE TO ORAL GLUCOSE LOADING

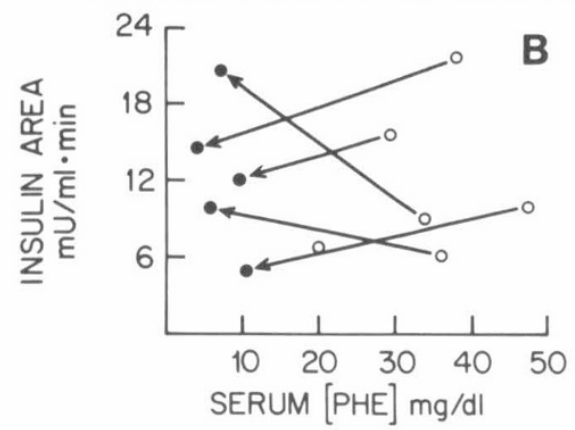

Fig. 1. $A$, glucose response to glucose loading $(1.75 \mathrm{~g} / \mathrm{kg})$. Total glucose area is calculated for $240 \mathrm{~min}$ and is expressed as $\mathrm{g} / \mathrm{dl} \cdot \mathrm{min}$. Serum phenylalanine $(P H E)$ is expressed as $\mathrm{mg} / \mathrm{dl}$. $\bigcirc$, obtained for the regular diet; , low phenylalanine diet. $B$, insulin response to glucose loading as above and is expressed as $\mathrm{mU} / \mathrm{ml} \cdot \mathrm{min}$. Each individual's values are connected by an arrow. Six values were obtained off diet, and 5 values were obtained on diet.

the conversion of phenylalanine to glucose and in part by an increase in glucagon secretion (17). We have confirmed that PO phenylalanine loading stimulates glucagon secretion in one treated phenylketonuric patient. Further studies are needed to determine

\section{GLUCOSE AND INSULIN RESPONSE TO GLUCOSE LOADING}

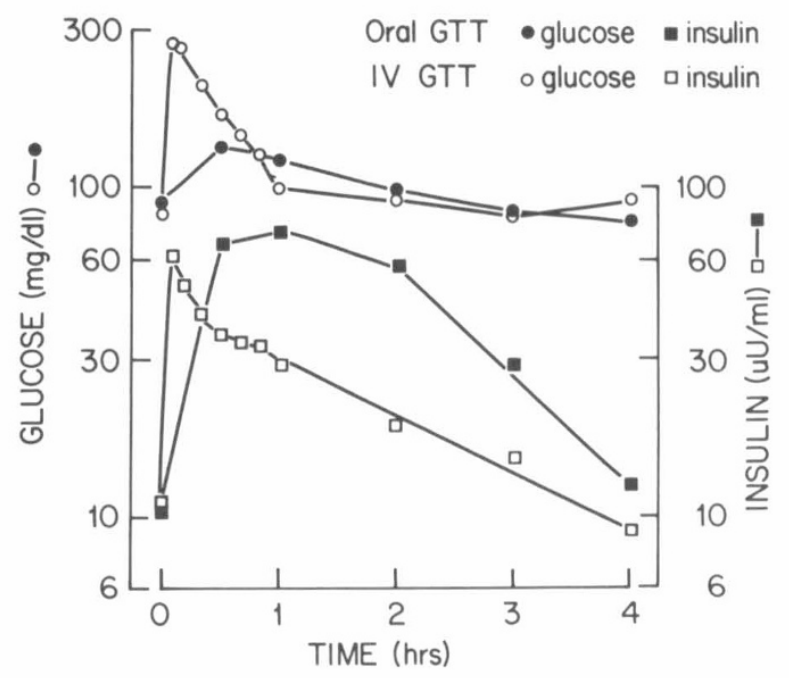

Fig. 2. Comparison of glucose and insulin responses to PO $(N=6)$ and IV $(N=4)$ glucose tolerance tests $(240 \mathrm{~min})$ in phenylketonurics on an unrestricted diet. $(1.75 \mathrm{~g} / \mathrm{kg}) ; \bigcirc$, glucose response; $\square$, insulin response to IV glucose $(0.5 \mathrm{~g} /$ $\mathrm{kg})$.

whether the glucagon stimulating effect of phenylalanine is diminished by chronic hyperphenylalanemia as seems to occur for its insulin secretagogic property. It seems plausible that hyposensitivity of the hormonal response to phenylalanine would develop in PKU patients on unrestricted diets. Otherwise, stimulation of insulin and glucagon release in PKU would be due primarily to this amino acid and the influence of other regulatory factors would be proportionately diminished.

In the present studies, we also administered glucose to challenge the pathways which produce and dispose of pyruvate. We found that basal levels of pyruvate and lactate in phenylketonuric subjects were normal, and only the expected modest increases in these levels occurred following glucose loading both off and on a low phenylalanine diet. These findings contrast with the observation of greatly elevated basal concentrations of pyruvate and lactate in 
the blood of several patients with untreated PKU (36) and of increased amounts of pyruvate in the urine of a patient with untreated PKU (24). The elevated pyruvate and lactate levels reported in three phenylketonuric (36) patients could have resulted from an inhibition of the pyruvate carboxylase and decarboxylase

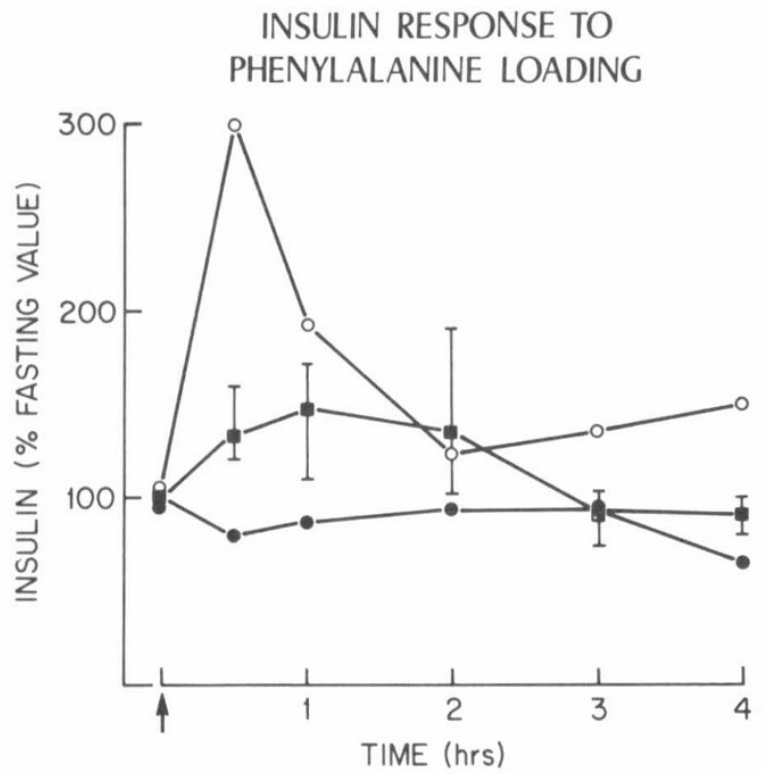

Fig. 3. Insulin response to acute PO phenylalanine loading (100 mg/ $\mathrm{kg})$ in normal controls $(N=3)$ and in subject 4 on a regular $(-)$ and a low phenylalanine diet $(O)$. Values are expressed as a percentage of fasting level. For the control group, the mean and range are shown. Fasting plasma insulin levels for subject 4 were 12.7 and $11.0 \mu \mathrm{U} / \mathrm{ml}$ off and on diet, respectively. The mean fasting level for controls was $16.8 \mu \mathrm{U} / \mathrm{ml}$. reactions by elevated phenylpyruvate. In these patients, the phenylalanine levels were 62,68 , and $38 \mathrm{mg} / \mathrm{dl}$, values which were considerably higher than those of the subjects we studied. If phenylpyruvate levels were also higher in these patients, this may account for the differences between studies. It does not appear, however, that elevation of blood lactate and pyruvate levels is a general phenomenon in PKU patients.

Inhibition by phenylalanine of pyruvate kinase, an enzyme which catalyzes the conversion of phosphoenolpyruvate to pyruvate, has been shown to occur in brain both in vitro (39) and in vivo (28). In rat liver and brain, phenylalanine competitively inhibits pyruvate kinase and leads to an increase in the intermediates of glycolysis from fructose-1, 6-diphosphate to phosphoenolpyruvate and to a decrease in pyruvate (14). Our results show that any inhibition of pyruvate kinase by phenylalanine was insufficient to prevent the normal rise in blood lactate and pyruvate after a glucose load.

Both on theoretical grounds and experimentally, it would appear that phenylalanine has a complex relationship with carbohydrate metabolism, especially when this amino acid is present in excess, as in PKU. It is possible that abnormalities in glucose uptake and utilization at the cellular level contribute to the pathogenesis of the brain disorder in untreated phenylketonuric infants. Major alterations in the parameters of carbohydrate metabolism after a glucose load were not observed in the blood, a fluid which predominantly reflects carbohydrate metabolism in liver and muscle. The absence of an increased insulin secretion following acute phenylalanine loading in the PKU patients suggests that chronic hyperphenylalaninemia blunts the insulinogenic response to acute phenylalanine stimulation.

\section{REFERENCES AND NOTES}

1. Abrams, M. E., Jarrett, R. J., Keen, H., Boyns, D. R., and Crossley, J. N.: Oral glucose tolerance and related factors in a normal population sample. Br. Med. J., 1: 599 (1969).

Table 3. Blood glucose, pyruvate, and lactate response in PKU patients to oral glucose and phenylalanine challenge

\begin{tabular}{ccccc}
$\begin{array}{c}\text { Treatment } \\
\text { diet }\end{array}$ & $\begin{array}{c}\text { Glucose } \\
\text { Low phenylalanine }\end{array}$ & $\begin{array}{c}\text { Glucose } \\
\text { regular }\end{array}$ & $\begin{array}{c}\text { Glucose + phenylalanine } \\
\text { Low phenylalanine }\end{array}$ & $\begin{array}{c}\text { Phenylalanin } \\
\text { Low phenylala }\end{array}$ \\
\hline Glucose $(\mu$ moles $/ \mathrm{ml})$ & & & & \\
F & $5.25 \pm 0.37^{2}$ & & & \\
30 & $9.35 \pm 1.03$ & $4.18 \pm 0.27^{3}$ & $4.73 \pm 0.09$ & $5.07 \pm 0.33$ \\
1 & $10.00 \pm 0.90$ & $6.47 \pm 0.88$ & $7.77 \pm 1.01$ & $4.80 \pm 0.37$ \\
2 & $7.20 \pm 1.36$ & $6.92 \pm 1.25$ & $5.93 \pm 1.07^{3}$ & $5.18 \pm 0.19$ \\
3 & $5.93 \pm 2.09$ & $6.37 \pm 1.74$ & $3.38 \pm 0.45$ & $5.22 \pm 0.24$ \\
4 & $4.87 \pm 0.22$ & $4.88 \pm 1.63$ & $3.98 \pm 0.28^{3}$ & $4.89 \pm 0.30$
\end{tabular}

Pyruvate $(\mu \mathrm{moles} / \mathrm{ml})$

$\begin{array}{rl}\mathrm{F} & 0.073 \pm 0.022 \\ 30 & 0.101 \pm 0.022 \\ 1 & 0.136 \pm 0.067 \\ 2 & 0.086 \pm 0.014 \\ 3 & 0.095 \pm 0.018 \\ 4 & 0.088 \pm 0.029\end{array}$

$0.074 \pm 0.020$
$0.072 \pm 0.013$
$0.087 \pm 0.020$
$0.143 \pm 0.045$
$0.101 \pm 0.011$
$0.111 \pm 0.037$

$$
\begin{aligned}
& 0.053 \pm 0.020 \\
& 0.054 \pm 0.022 \\
& 0.062 \pm 0.028 \\
& 0.048 \pm 0.020 \\
& 0.043 \pm 0.023 \\
& 0.039 \pm 0.020
\end{aligned}
$$

$0.063 \pm 0.019$

$0.052 \pm 0.014$

$0.051 \pm 0.016$

$0.045 \pm 0.017$

$0.043 \pm 0.015$

$0.039 \pm 0.013$

Lactate $(\mu \mathrm{moles} / \mathrm{ml})$

$\begin{array}{rr}\mathrm{F} & 0.95 \pm 0.49 \\ 30 & 1.29 \pm 0.16 \\ 1 & 1.44 \pm 0.62 \\ 2 & 1.33 \pm 0.07 \\ 3 & 1.21 \pm 0.12 \\ 4 & 1.18 \pm 0.16\end{array}$

$1.09 \pm 0.30$
$1.37 \pm 0.17$
$1.48 \pm 0.10$
$1.35 \pm 0.15$
$1.04 \pm 0.19$
$1.01 \pm 0.24$

$0.86 \pm 0.32$

$0.67 \pm 0.06$

$0.63 \pm 0.07$

$0.56 \pm 0.05$

$0.58 \pm 0.03$

$0.51 \pm 0.10$

\footnotetext{
${ }^{1}$ Bloods were collected by venipuncture and immediately mixed with $1 \mathrm{~N}$ perchloric acid and frozen in dry ice until processed. After thawing and centrifugation at $15,000 \times g$, the supernatants were neutralized with $\mathrm{KOH}$ and assayed for glucose, lactate, and pyruvate.

${ }^{2}$ Mean \pm S.E. for the three subjects studied on and off the low phenylalanine diet following feeding of glucose, phenylalanine, or both at time 0 .

${ }^{3}$ Significance at the $5 \%$ level in the comparison with patients on the diet receiving glucose alone, by Student's $t$ test. Only the two other conditions in which glucose was administered are compared and not the condition when phenylalanine alone was given.
} 
2. Aguilar-Parada, E., Eisentraut, A. M., and Unger, R. H.: Pancreatic glucagon secretion in normal and diabetic subjects. Am. J. Med. Sci., 257: 415 (1969).

3. Ambrose, J. A.: Fluorometric measurements of tyrosine in serum and plasma. Clin. Chem., 20: 505 (1974).

4. Ambrose, J. A., Ingerson, A., Garrettson, L. G., and Chung, C. W.: A study of the fluorometric method for phenylalanine in serum samples. Clin. Chim. Acta, 15: 493 (1967).

5. Cardenas, J. M., Stravidholm, J. J., and Miller, J. M.: Effects of phenylalanine and alanine on the kinetics of bovine pyruvate kinase isozymes. Biochemistry, 14: 4041 (1975).

6. Castells, S., Grunt, J. A., and Brandt, I. K.: Changes in plasma growth hormone after a phenylalanine tolerance test in normal and phenylketonuric children. J. Pediatr., 75: 820 (1969).

7. Clayton, B. E., Moncrieff, A. A., Pampiglione, G., and Shepherd, J.: Biochemical and EEG studies in phenylketonuric children during phenylalanine tolerance tests. Arch. Dis. Child., 41: 267 (1966).

8. Crane, R.: $\mathrm{Na}^{+}$-dependent transport in the intestine and other animal tissues. Fed. Proc., 24: 1000 (1965).

9. Cunningham, G. C., Day, R. W., Berman, J. L., and Hsia, D. Y.: Phenylalanine tolerance tests: in families with phenylketonuria and hyperphenylalaninemia. Am. J. Dis. Child., 117: 626 (1969).

10. Dodge, P. R., Mancall, E. L., Crawford, J. D., Knapp, J., and Paine, R. S. Hypoglycemia complicating treatment of phenylketonuria with phenylalaninedeficient diet. N. Engl. J. Med., 260: 1104 (1959).

11. Fajans, S. S., Floyd, J. D., Knopf, R. F., and Conn, J. W.: Effects of amino acids and proteins on insulin secretion in man. Recent Prog. Horm. Res., 23: 617 (1967).

12. Felig, P., Marliss, E., and Cahill, G. F., Jr.: Plasma amino acid levels and insulin secretion in obesity. N. Engl. J. Med., 281: 811 (1969).

13. Floyd, J. C., Jr., Fajans, S. S., Conn, J. W., Knoff, R. F., and Rull, J.: Stimulation of insulin secretion by amino acids. J. Clin. Invest., 45: 1487 (1966).

14. Giminez, C., Validvieso, F., and Mayor, F.: Glycolysis in the brain and liver of rats with experimentally induced phenylketonuria. Biochem. Med., 11: 81 (1974).

15. Glazer, R. I., and Weber, G.: The effects of L-phenylalanine and phenylpyruvate on glycolysis in rat cerebral cortex. Brain Res., 33: 439 (1971).

16. Glazer, R. I., and Weber, G.: The effects of phenylpyruvate and hyperphenylalaninemia on the incorporation of $\left(6-{ }^{3} \mathrm{H}\right)$ glucose into macromolecules of slices of rat cerebral cortex. J. Neurochem., 18: 2371 (1971).

17. Güttler, F., Kühl, C., Pedersen, L., and Pảby, P.: Effects of oral phenylalanine load on plasma glucagon, insulin, amino acid and glucose concentrations in man. Scand. J. Clin. Lab. Invest., 38: 255 (1978).

18. Heffernan, A. G.: Glucose tolerance and insulin response in phenylketonuria. N. Engl. J. Med., 285: 57 (1971).

19. Holes, C. N., and Randle, P. J.: Immunoassay of insulin with insulin antibody precipitate. Lancet, 1: 200 (1963).

20. Kamaryt, J., and Mrskos, A.: Is the inhibition of glutamic pyruvic transaminase by phenylalanine one of the causes of hypoglucosemia in phenylketonurics? Acta Univ. Carol Med. Monogr., 56: 187 (1973).

21. Land, J. M., and Clark, J. B.: Effect of phenylpyruvate on pyruvate dehydrogenase activity in rat brain mitochondria. Biochem. J., 134: 539 (1973).

22. Land, J. M., and Clark, J. B.: Effect of phenylpyruvate on enzymes involved in fatty acid synthesis in rat brain. Biochem. J., 134: 545 (1973).

23. Landgraf, R., Landgraf-Leurs, M. M. C., and Hörl, R.: L-Leucine and L-phenylalanine induced insulin release and the influence of $\mathrm{D}$-glucose: kinetic studies with the perfused rat pancreas. Diabetologia, 10: 415 (1974).

24. Lonsdale, D., Price, J. W., and Shamberger, R. J.: Pyruvate decarboxylase inhibition in ketoaciduria. Pediatr. Res., 5: 396 (1971).

25. Lowry, O. H., and Passonneau, J.: A Flexible System of Enzymatic Analysis. (Academic Press, Inc., New York, 1972).

26. Marholin D., II, Pohl R. E., III., Stewart, R. M., Townsend, N. M., Touchette, P. E., and Kolodny, E. H.: Effects of diet and behavior therapy on social and motor behavior of retarded phenylketonuric adults: an experimental analysis. Pediatr. Res., 12: 179 (1978)

27. Marks, V.: An improved glucose-oxidase method for determining blood, C. S. F. and urine glucose levels. Clin. Chim. Acta, 4: 395 (1959).

28. Miller, A. L., Hawkins, R. A., and Veech, R. L.: Phenylketonuria: Phenylalanine inhibits brain pyruvate kinase in vivo. Science (Wash. D. C.), 179: 904 (1973).

29. Mitoma, C., and LeValley, S. E.: Transport and incorporation of labeled compounds in experimental phenylketonuric rats. Proc. Soc. Exp. Biol. Med., 144: 710 (1973).

30. Mrskos, A., Kaniova, V., Podhradska, O., Drailova, L., and Snopkova, J.: Impaired glucose homeostasis in phenylketonurics. Acta Univ. Carol Med. Monogr., 56: 197 (1973).

31. Pallotta, J. A., and Kennedy, P. J.: Response of plasma insulin and growth hormone to carbohydrate and protein feedings. Metabolism, 17: 901 (1968).

32. Patel, M. S.: The effect of phenylpyruvate on pyruvate metabolism in rat brain. Biochem. J., 128: 677 (1972).

33. Patel, M. S., Grover, W. D., and Auerbach, V. H.: Pyruvate metabolism by homogenates of human brain: effects of phenylpyruvate and implications for the etiology of mental retardation in phenylketonuria. J. Neurochem., 20: 289 (1973).

34. Shah, S. N., Peterson, N. A., and McKean, C. M.: Cerebral lipid metabolism in experimental hyperphenylalaninaemia: incorporation of ${ }^{14} \mathrm{C}$-labeled glucose into total lipids. J. Neurochem., 17: 279 (1970).

35. Stewart, R. M., Hemli, S., Daniels, G. H., Kolodny, E. H., and Maloof, F.: The pituitary-thyroid axis in adults with phenylketonuria. J. Clin. Endocrinol. Metab., 42: 1179 (1976)

36. Sutnick, M., Grover, W., and Patel, M.: Impairment of hepatic pyruvate metabolism in phenylketonuria. Life Sci., 15: 1945 (1975).

37. Valdivieso, F., Ugarte, M., Maties, M., Gimenez, C., and Mayor, F.: Free amino acids in the tissues of rats with experimentally induced phenylketonuria. J. Ment. Defic. Res., 21: 95 (1977).

38. Wapnir, R. A., and Lifshitz, F.: Intestinal transport of aromatic amino acids, glucose and electrolytes in a patient with phenylketonuria. Clin. Chim. Acta, 54: 349 (1974).

39. Weber, G.: Inhibition of human brain pyruvate kinase and hexokinase by phenylalanine and phenylpyruvate: possible relevance to phenylketonuric brain damage. Proc. Natl. Acad. Sci. U. S. A., 63: 1365 (1969).

40. Yalow, R. S., and Berson, S. A.: Immunoassay of endogenous plasma insulin in man. J. Clin. Invest., 39: 1157 (1960).

41. The authors are especially indebted to Nancy Clark and Julia Seidel, dieticians, who ably supervised the preparation of the low phenylalanine foods and carefully monitored each patient's dietary intake.

42. Requests for reprints should be addressed to: R. Malcolm Stewart, M.D., Neurology Department, University of Texas Health Science Center, 5323 Harry Hines Blvd., Dallas, TX 75235 (USA).

43. This research was supported in part by USPHS Grants HD-05515 and HD04147 to the Shriver Center (E. H. K.); BRSG grant B75-39 to Massachusetts General Hospital (R. M. S.); and grant HD-09519 and MH-16674 to the Massachusetts General Hospital and McLean Hospital (A. L. M.).

44. Received for publication October 31, 1979

45. Accepted for publication October 18, 1979 